\title{
Fatigue Damage Estimation in Existing Railway Steel Bridges by Detailed Loading History Analysis
}

\author{
Alessio Pipinato, Carlo Pellegrino, and Claudio Modena \\ Department of Structural and Transportation Engineering, University of Padova, Via Marzolo 9, 35131 Padova, Italy \\ Correspondence should be addressed to Alessio Pipinato, alessio.pipinato@unipd.it
}

Received 6 February 2012; Accepted 2 April 2012

Academic Editors: Z. Li and I. Raftoyiannis

Copyright (C) 2012 Alessio Pipinato et al. This is an open access article distributed under the Creative Commons Attribution License, which permits unrestricted use, distribution, and reproduction in any medium, provided the original work is properly cited.

\begin{abstract}
Fatigue life estimation of metal historical bridges is a key issue for managing cost-effective decisions regarding rehabilitation or replacement of existing infrastructure. Because of increasing service loads and speeds, this type of assessment method is becoming relevant. Hence there is a need to estimate how long these structures could remain in service. In this paper a method to estimate fatigue damage in existing steel railway bridges by detailed loading history analysis is presented. The procedure is based on the assumption that failure probability is a function of the number of predicted future trains and the probability of failure is related to the probability of reaching the critical crack length.
\end{abstract}

\section{Introduction}

A relevant amount of the bridges in the European railway networks are metal made and have been built during the last 100 years. The increasing volume of traffic and axle weight of trains means that the current loads are much higher than those envisaged when the bridge was designed. In this context, issues as maintenance, assessment, rehabilitation, and strengthening of existing bridges assume a significant importance $[1,2]$. The authors have developed some works concerning assessment and fatigue behavior of metal railway bridges by means of full-scale experimental testing. In particular in Pipinato et al. [3, 4] full-scale tests on dismantled steel bridges have been developed, whereas assessment of existing bridges and estimation of their remaining fatigue life are shown in Pipinato and Modena [5] and Pipinato et al. [6]. Moreover, a comprehensive method to assess the reliability of existing bridges taking fatigue into account has been recently published [7]. Among historical metal bridges, riveted structures are the most common; the role of riveted connections in the fatigue assessment is documented by several researches, such as, in Bruhwiler et al. [8], Kulak [9], Akesson and Edlund [10], Di Battista et al. [11], Bursi et al. [12], Matar and Greiner [13], Boulent et al. [14],
Albrecht and Lenwari [15], Kühn et al. [16], Albrecht and Lenwari [17], and Brühwiler et al. [18]. Fatigue is one of the most common causes of failure in riveted bridges, as highlighted by the ASCE Committee on Fatigue and Fracture Reliability [19] and confirmed by Byers et al. [20]. Increasing loads on existing riveted bridges and the fact that these bridges were not explicitly designed against fatigueraised questions regarding their remaining fatigue life. As a consequence, a better knowledge of the loading history is needed, having a relevant role in the fatigue damage assessment. The fatigue damage mainly depends on the following three main parameters: the stress range amplitude due to traffic load; the geometry of the construction details; the number of stress cycles due to the past traffic which directly influences the remaining fatigue life of a structure. In the context of structural reliability assessment, a comprehensive examination of fatigue safety and remaining service life of railway bridges is based on these three main parameters. The main objective of this paper is to estimate the fatigue damage in existing railway metal bridges and at the same time to determine the remaining fatigue life according to a step-by-step procedure referring to the LEFM (Linear Elastic Fracture Mechanics) theory by means of detailed loading history analysis. The method is then applied to a real case 

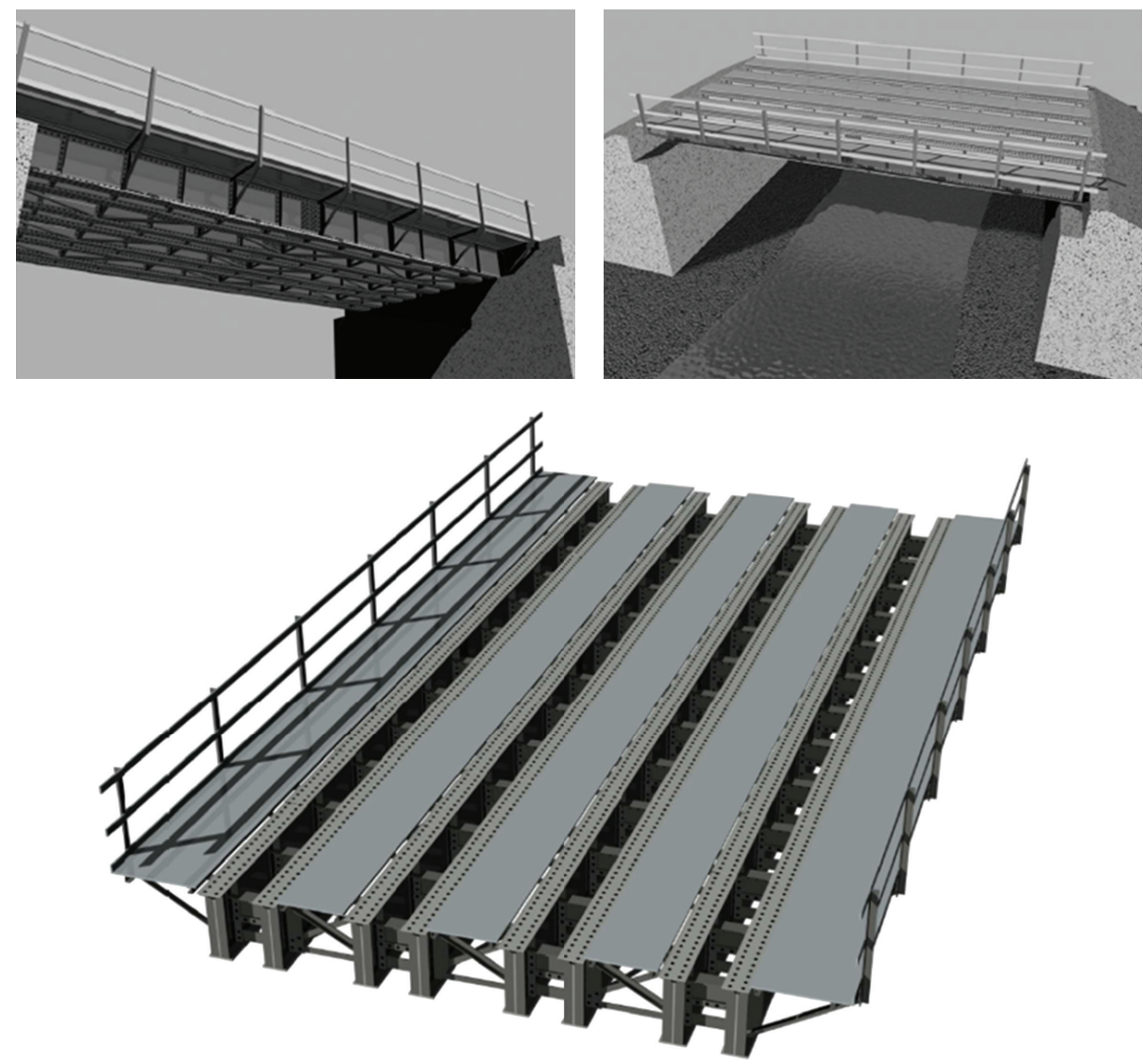

FIgURE 1: Dimensional overviews of the Meschio bridge.

study, the Meschio railway bridge briefly described in the following paragraph.

\section{Case Study}

The Meschio bridge, a short span riveted flanged railway bridge built in 1918, was taken out of service in 2005 (Figure 1). It has been used in the line Mestre-Cormons, which is located in the North-eastern part of Italy. The net span of the bridge was $12.40 \mathrm{~m}$. The main horizontal structure was made of two couples of twinned riveted composite flange beams. Wooden beams were located between the coupled beams, with a net distance of $565 \mathrm{~mm}$ from web to web of the beams, while the beam height was $838 \mathrm{~mm}$. In this open-deck riveted railway bridge, transversal short shear diaphragms are riveted with double angles to both webs carried the rails. Each twinned beam supported the wooden elements of a single rail. The thickness of the main beam plates was $11 \mathrm{~mm}$. The web was reinforced by $1 \mathrm{~m}$ spaced shear stiffeners, whereas the flanges were reinforced with $10 \mathrm{~mm}$ thick plates. The plate thickness increased from the abutment to the midspan. Each pair of twinned beams was linked to the corresponding pair with transverse bracing frames. The characteristics of the materials and more details on the geometry are described in Pipinato et al. [3, 4], while a typical cross section has been reported in Figure 2. Because the examined bridge was characterized by a simple structure, that is, a statically determinate bridge, it was rather easy to evaluate the nominal stress on members and connections of the bridge. In order to check these results, a stress analysis has been performed with a simplified FEM model, calibrated with observed strains derived from real scale testing results $[3,4]$.

2.1. Load History Assumption. Railway traffic estimation has been based on International Union of Railways, UIC [21] and on real data observed in the railway network from 1900 to 1990. A quadratic polynomial regression based on these data was performed and used for future traffic estimation (Figure 3). The maximum traffic capacity of the railway line in which the bridge is included has been assumed equal to 235 trains/day, following to the maximum capacity of the main national railway lines. According to these assumptions, the adopted traffic model are shown in Figures 3 and 4: the past real traffic and its growth tendency by adopting the UIC regression is shown in Figure 3, while the capacity of the line is developed in Figure 4 according to different traffic trend evolution, until a maximum of 235 trains/day. Figure 4 shows the traffic estimation from 1900 to 2020, with increasings of $1 \%, 2 \%, 3 \%$ and the UIC regression tendency (percentage increasing versus time) to estimate the number of trains passed on the bridge. UIC traffic data have been considered 


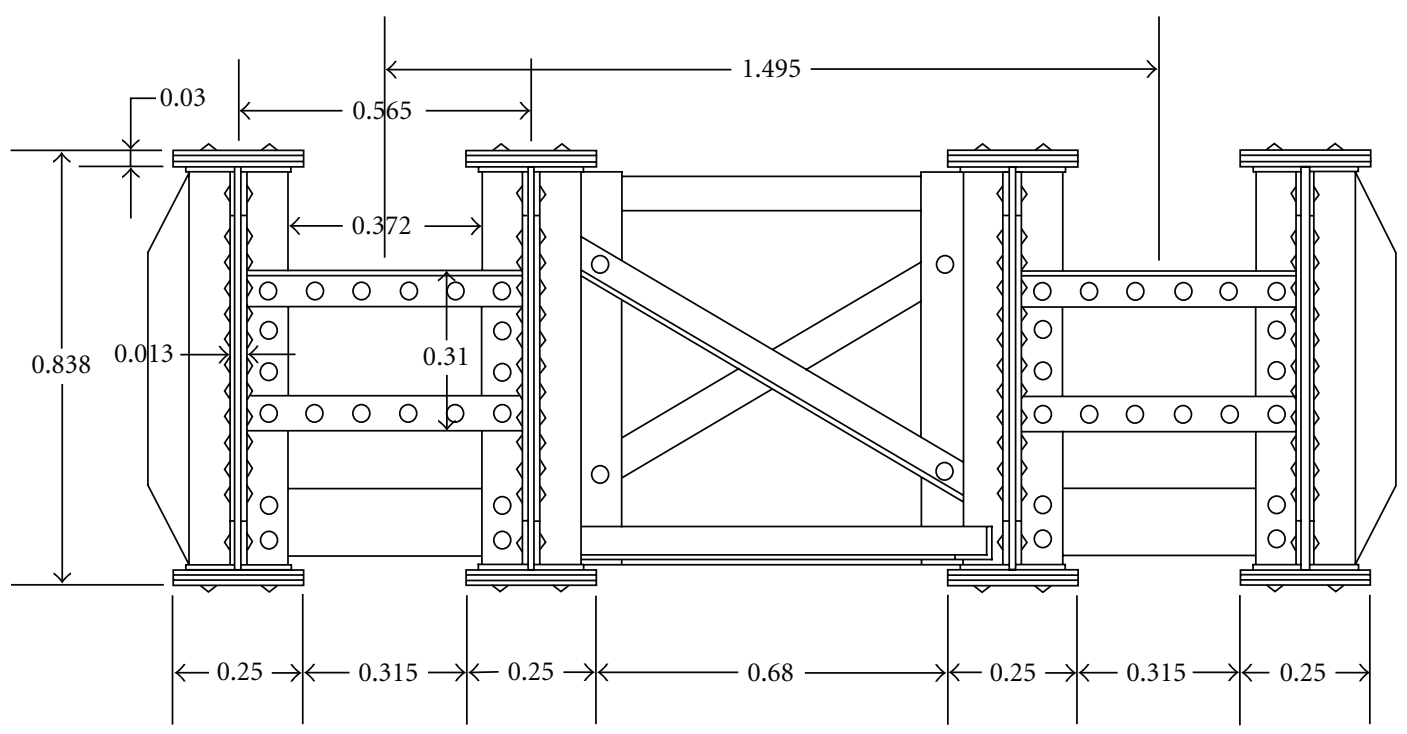

Figure 2: Cross section of the of the Meschio bridge girder at midspan.

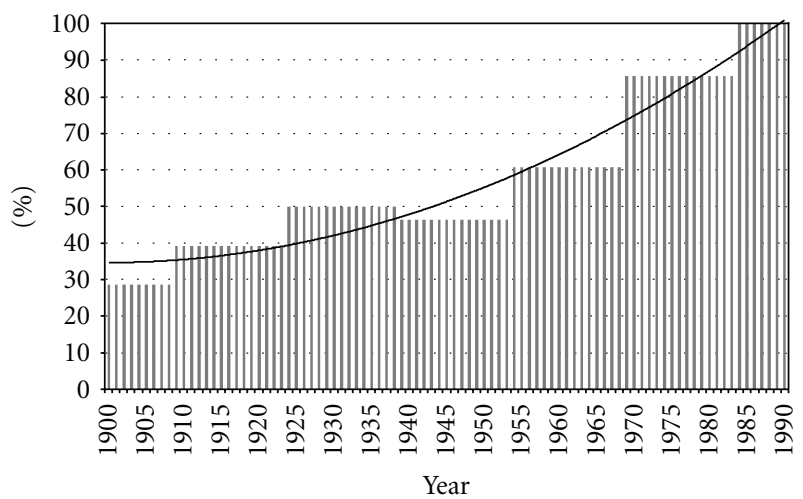

FIgURE 3: Traffic increment regression based on UIC [21] real train (percentage increment versus time).

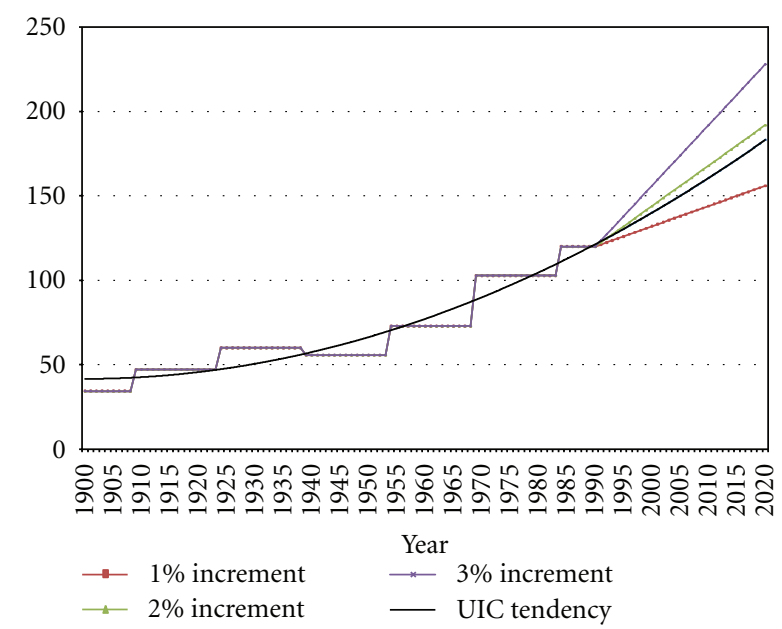

FIgURE 4: Traffic estimation from 1900 to 2020, with increments of $1 \%, 2 \%, 3 \%$ and UIC regression tendency (percentage increment versus time). for the past, whereas some assumptions have been proposed for the future. The method described in the following is based on the aforementioned traffic estimation, and this scenario is also in accordance with CER [23]: in fact for the period 1995-2004, CER traffic increase is of $16 \%$, just like UIC traffic increase. The past traffic has been assumed with a rate of $50 \%$ of passengers and $50 \%$ of freight trains [24]. Traffic assumption includes train type and convoy numbers: from 1900 to 1990 these data are presented in Table 1, while from 1991-2000 traffic was estimated according to Instruction 44/F [25], as described in Table 2. As a matter of fact, load models have been implemented as they were coded in the different historical periods analyzed:

(i) the historical loadings have been assumed according to UIC 779-1 [21];

(ii) from 1991 to 2000, the traffic spectrum has been based on the Instruction 44/F [25];

(iii) from 2001 up to now, loads refers to LM71 (Figure 5; [22]) load model (method A) or to Instruction 44/F $(\operatorname{method} B)[25]$.

For historical trains and for Instruction $44 / F$ trains, dynamic amplification factor $\varphi$ is calculated according to EN 1991-2 [22]:

$$
\varphi=1+\frac{1}{2\left(\varphi^{\prime}+1 / 2 \varphi^{\prime \prime}\right)},
$$

where:

$$
\begin{gathered}
\varphi^{\prime}=\frac{K}{1-K+K^{4}}, \\
K=\frac{v}{160} \quad \text { for } L<20 \mathrm{~m}, \\
K=\frac{v}{47.16 \cdot L^{0.408}} \quad \text { for } L>20 \mathrm{~m}, \\
\varphi^{\prime \prime}=0.56 \cdot e^{-L^{2} / 100},
\end{gathered}
$$


TABLE 1: Traffic type for the historical train (1900-1990).

\begin{tabular}{|c|c|c|c|c|c|}
\hline Period & Train/day & Type & UIC ref. & Train type [\%] & Train/day for type \\
\hline \multirow{3}{*}{ 1900-1908 } & 34,3 & Tot. & & & \\
\hline & 17,2 & Passenger & $\mathrm{A} 03$ & $100 \%$ & 17,2 \\
\hline & 17,2 & Freight & A04 & $100 \%$ & 17,2 \\
\hline \multirow{4}{*}{ 1909-1923 } & 47,2 & Tot. & & & \\
\hline & 23,6 & Passenger & A05 & $60 \%$ & 14,1 \\
\hline & & & A06 & $40 \%$ & 9,4 \\
\hline & 23,6 & Freight & $\mathrm{A} 07$ & $100 \%$ & 23,6 \\
\hline \multirow{5}{*}{ 1924-1938 } & 60,0 & Tot. & & & \\
\hline & 30,0 & Passenger & A08 & $60 \%$ & 18,0 \\
\hline & & & A09 & $40 \%$ & 12,0 \\
\hline & 30,0 & Freight & $\mathrm{A} 07$ & $60 \%$ & 18,0 \\
\hline & & & $\mathrm{A} 10$ & $40 \%$ & 12,0 \\
\hline \multirow{5}{*}{ 1939-1953 } & 55,7 & Tot. & & & \\
\hline & 27,8 & Passenger & A11 & $50 \%$ & 13,9 \\
\hline & & & A12 & $50 \%$ & 13,9 \\
\hline & 27,8 & Freight & A 10 & $60 \%$ & 16,7 \\
\hline & & & A13 & $40 \%$ & 11,1 \\
\hline \multirow{7}{*}{ 1954-1968 } & 72,8 & Tot. & & & \\
\hline & 36,4 & Passenger & A14 & $25 \%$ & 9,1 \\
\hline & & & A15 & $17 \%$ & 6,2 \\
\hline & & & A17 & $33 \%$ & 12,0 \\
\hline & & & A18 & $25 \%$ & 9,1 \\
\hline & 36,4 & Freight & A16 & $40 \%$ & 14,6 \\
\hline & & & $\mathrm{A} 20$ & $60 \%$ & 21,9 \\
\hline \multirow{6}{*}{ 1969-1983 } & 102,8 & Tot. & & & \\
\hline & 51,4 & Passenger & $\mathrm{A} 14$ & $28 \%$ & 14,4 \\
\hline & & & A18 & $36 \%$ & 18,5 \\
\hline & & & A19 & $36 \%$ & 18,5 \\
\hline & 51,4 & Freight & A20 & $40 \%$ & 20,6 \\
\hline & & & A21 & $60 \%$ & 30,9 \\
\hline \multirow{7}{*}{ 1984-1990 } & 120,0 & Tot. & & & \\
\hline & 60,0 & Passenger & S01 & $56 \%$ & 33,6 \\
\hline & & & S02 & $44 \%$ & 26,4 \\
\hline & 60,0 & Freight & $\mathrm{S} 03$ & $37 \%$ & 22,2 \\
\hline & & & S04 & $37 \%$ & 22,2 \\
\hline & & & S05 & $13 \%$ & 7,8 \\
\hline & & & S06 & $13 \%$ & 7,8 \\
\hline
\end{tabular}

where $v$ is the train speed $(\mathrm{m} / \mathrm{s})$ and $L$ is the determinant length $L_{F}(\mathrm{~m})$. For LM71 load model (method A), the dynamic amplification factor has been calculated according to EN 1991-2 [22]

$$
\phi_{3}=\frac{2,16}{\sqrt{L_{\phi}}-0,2}+0,73
$$

assuming $1,00 \leq \Phi_{3} \leq 2,00$, and $L_{F}=$ determinant length. All the dynamic amplification factors applied have been reported in Table 3 .
2.2. Assessment Procedure. The assessment method is based on a probabilistic evaluation of the reliability margin $G$ defined in the form:

$$
G=R-E \geq 0
$$

where $R$ is the structural resistance and $E$ represents action effects. The probability of failure is defined as:

$$
P_{f}=P(G<0)=P(R-E<0) .
$$


TABle 2: Traffic type for the period 1991-2000.

\begin{tabular}{|c|c|c|c|c|c|c|c|c|}
\hline Train type & Name & Train/day & Axle/day & $\begin{array}{l}\text { Locomotive }(\mathrm{L}) \\
\text { and carriages }(\mathrm{Ci})\end{array}$ & t/axle & Wagon number & Wagon type & Axle spacing $[\mathrm{m}]$ \\
\hline \multirow{3}{*}{1} & IC & 20 & 960 & $\mathrm{~L}$ & 20,25 & 1 & $\downarrow \downarrow \quad \downarrow \downarrow$ & $2.6-6.4-2.6$ \\
\hline & Intercity & & & $\mathrm{C} 1$ & 15 & 5 & $\downarrow \downarrow \quad \downarrow \downarrow$ & $2.56-16.44-2.56$ \\
\hline & & & & $\mathrm{C} 2$ & 12,75 & 6 & $\downarrow \downarrow \quad \downarrow \downarrow$ & $2.56-16.44-2.56$ \\
\hline \multirow{3}{*}{2} & $\mathrm{EC}$ & 10 & 340 & $\mathrm{~L}$ & 20 & 1 & $\downarrow \downarrow \downarrow \downarrow \downarrow \downarrow$ & $2.85-2.35-2.85-2.35-2.85$ \\
\hline & Eurocity & & & $\mathrm{C} 1$ & 14,25 & 2 & $\downarrow \downarrow \quad \downarrow \downarrow$ & 2.56-16.44-2.56 \\
\hline & & & & $\mathrm{C} 2$ & 12 & 5 & $\downarrow \downarrow$ & $2.56-16.44-2.56$ \\
\hline \multirow{3}{*}{3} & EXPR & 15 & 990 & $\mathrm{~L}$ & 20 & 1 & $\downarrow \downarrow \downarrow \downarrow \downarrow \downarrow$ & $2.85-2.35-2.85-2.35-2.85$ \\
\hline & Express & & & $\mathrm{C} 1$ & 14,25 & 10 & $\downarrow \downarrow \quad \downarrow \downarrow$ & $2.56-16.44-2.56$ \\
\hline & & & & $\mathrm{C} 2$ & 12 & 5 & $\downarrow \downarrow \quad \downarrow \downarrow$ & $2.56-16.44-2.56$ \\
\hline \multirow{2}{*}{4} & DIR & 30 & 1380 & $\mathrm{~L}$ & 18,6 & 1 & $\downarrow \downarrow \downarrow \downarrow \downarrow \downarrow$ & $2.85-2.35-2.85-2.35-2.85$ \\
\hline & Direct & & & $\mathrm{C} 1$ & 10,675 & 10 & $\downarrow \downarrow \quad \downarrow \downarrow$ & 2.4-16.6-2.4 \\
\hline \multirow{2}{*}{5} & ETR & 10 & 480 & $\mathrm{~L}$ & 20 & 2 & $\sqrt{\downarrow}$ & $3-9-3$ \\
\hline & Eurostar & & & $\mathrm{C} 1$ & 11,6 & 10 & $\sqrt{\downarrow}$ & $3-17.3-3$ \\
\hline \multirow{2}{*}{6} & TEC & 15 & 990 & $\mathrm{~L}$ & 18,7 & 1 & $\downarrow \downarrow \downarrow \downarrow \downarrow \downarrow$ & $2.85-2.35-2.85-2.35-2.85$ \\
\hline & $\begin{array}{l}\text { Container } \\
\text { freight }\end{array}$ & & & $\mathrm{C} 1$ & 20 & 15 & $\downarrow \downarrow \quad \downarrow \downarrow$ & $1.8-12.8-1.8$ \\
\hline \multirow[t]{2}{*}{7} & $\begin{array}{c}\text { Merci } \\
\text { acciaio }\end{array}$ & 10 & 720 & $\mathrm{~L}$ & 18,7 & 2 & $\downarrow \downarrow \downarrow \downarrow \downarrow \downarrow$ & $2.85-2.35-2.85-2.35-2.85$ \\
\hline & $\begin{array}{l}\text { Steel } \\
\text { freight }\end{array}$ & & & $\mathrm{C} 1$ & 20 & 15 & $\downarrow \downarrow \quad \downarrow \downarrow$ & $1.8-13.06-1.8$ \\
\hline \multirow[t]{2}{*}{8} & $\begin{array}{c}\text { Treno } \\
\text { merci } \\
\text { tipo D4 }\end{array}$ & 5 & 380 & $\mathrm{~L}$ & 20 & 2 & $\downarrow \downarrow \downarrow \downarrow \downarrow$ & $2.85-2.35-2.85-2.35-2.85$ \\
\hline & $\begin{array}{c}D 4 \\
\text { freight }\end{array}$ & & & $\mathrm{C} 1$ & 22,5 & 16 & $\downarrow \downarrow$ & $1.8-4.65-1.8$ \\
\hline \multirow[t]{2}{*}{9} & $\begin{array}{l}\text { Treno } \\
\text { merci } \\
\text { misto }\end{array}$ & 5 & 270 & $\mathrm{~L}$ & 18,7 & 1 & $\downarrow \downarrow \downarrow \downarrow \downarrow \downarrow$ & $2.85-2.35-2.85-2.35-2.85$ \\
\hline & $\begin{array}{l}\text { Mixed } \\
\text { freight }\end{array}$ & & & $\mathrm{C} 1$ & 16 & 24 & $\downarrow$ & 9 \\
\hline
\end{tabular}

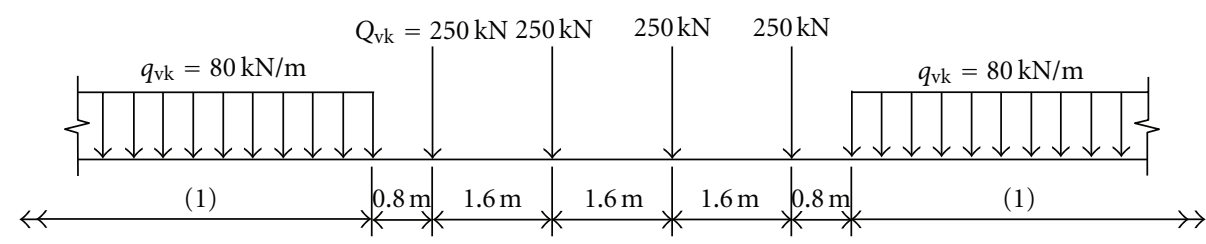

Figure 5: Load Model 71 according to EN 1991-2 [22].

Assuming statistical independence of $R$ and $E$, the probability of failure can be defined as:

$$
P_{f}=\int_{-\infty}^{\infty} f_{E}(x) \phi_{R}(x) d x
$$

where $\phi_{R}(x)$ is the cumulative function distribution of structural resistance $R$,

$$
P(R<x)=\phi_{R}(x) .
$$

$f_{E}(x)$ expresses probability occurrence of action effects $E$ in the near of the point $x$

$$
P\left(\frac{x-d x}{2} \leq E \leq \frac{x+d x}{2}\right)=f_{E}(x) d x .
$$

As a consequence, the probability of failure could be expressed as:

$$
P_{f}=\int_{-\infty}^{0} f_{G}(G) d G
$$


TABle 3: Dynamic amplification factor (detail 1).

\begin{tabular}{|c|c|c|c|c|c|}
\hline Period & Train type & Train name & Speed $[\mathrm{km} / \mathrm{h}]$ & D.A.F. [dynamic amplification factor] $\varphi, \phi_{3}$ & Code ref. \\
\hline $1900-1983$ & Passenger/freight & $\mathrm{A} 03 / \mathrm{A} 21$ & 100 & 1,135 & UIC \\
\hline \multirow[t]{6}{*}{ 1984-1990 } & Passenger & S01 & 125 & 1,168 & UIC \\
\hline & Passenger & S02 & 140 & 1,190 & UIC \\
\hline & Freight & S03 & 80 & 1,111 & UIC \\
\hline & Freight & S04 & 80 & 1,111 & UIC \\
\hline & Freight & S05 & 80 & 1,111 & UIC \\
\hline & Freight & S06 & 80 & 1,111 & UIC \\
\hline \multirow[t]{9}{*}{ 1991-2000 } & Passenger & IC & 200 & 1,290 & Instr.44/f \\
\hline & Passenger & EC & 160 & 1,221 & Instr.44/f \\
\hline & Passenger & EXPR & 150 & 1,205 & Instr.44/f \\
\hline & Passenger & DIR & 140 & 1,190 & Instr.44/f \\
\hline & Passenger & ETR & 250 & 1,391 & Instr.44/f \\
\hline & Freight & TEC & 120 & 1,161 & Instr.44/f \\
\hline & Freight & Merci & 100 & 1,135 & Instr.44/f \\
\hline & Freight & Treno merci & 100 & 1,135 & Instr.44/f \\
\hline & Freight & Treno merci & 120 & 1,161 & Instr.44/f \\
\hline 2001-: & Fatigue load & LM 71 & - & 1,380 & EN1991-2 \\
\hline
\end{tabular}

TABle 4: Damage accumulation from 1918.

\begin{tabular}{|c|c|c|c|c|}
\hline$D=\sum d_{i}$ & $\mathrm{Nc}$ & $d_{i}$ & $R_{i}$ & $d_{i} \times R_{i}$ \\
\hline \multicolumn{5}{|c|}{ Train A03 (1900-1908) } \\
\hline $0,000 E+00$ & $2,0 E+06$ & 0,0000000097 & $0,0 E+00$ & 0,000 \\
\hline $0,000 E+00$ & $2,0 E+06$ & 0,0000000097 & $0,0 E+00$ & 0,000 \\
\hline $0,000 E+00$ & $2,0 E+06$ & 0,0000000097 & $0,0 E+00$ & 0,000 \\
\hline \multicolumn{5}{|c|}{ Train A04 (1900-1908) } \\
\hline $0,000 E+00$ & $2,0 E+06$ & 0,0000001823 & $0,0 E+00$ & 0,000 \\
\hline $0,000 E+00$ & $2,0 E+06$ & 0,0000001823 & $0,0 E+00$ & 0,000 \\
\hline $0,000 E+00$ & $2,0 E+06$ & 0,0000001823 & $0,0 E+00$ & 0,000 \\
\hline \multicolumn{5}{|c|}{ Train A05 (1909-1923) } \\
\hline $0,000 E+00$ & $2,0 E+06$ & 0,0000003146 & $6,2 E+04$ & 0,019 \\
\hline $1,950 E-02$ & $2,0 E+06$ & 0,0000003193 & $6,2 E+04$ & 0,020 \\
\hline $3,928 E-02$ & $2,0 E+06$ & 0,0000003235 & $1,2 E+05$ & 0,040 \\
\hline $7,938 E-02$ & $2,0 E+06$ & 0,0000003305 & $1,9 E+05$ & 0,061 \\
\hline $1,408 E-01$ & $2,0 E+06$ & 0,0000003385 & $2,8 E+05$ & 0,094 \\
\hline \multicolumn{5}{|c|}{ Train A06 (1909-1923) } \\
\hline $2,352 E-01$ & $2,0 E+06$ & 0,0000004895 & $4,1 E+04$ & 0,020 \\
\hline $2,554 E-01$ & $2,0 E+06$ & 0,0000004896 & $4,1 E+04$ & 0,020 \\
\hline $2,757 E-01$ & $2,0 E+06$ & 0,0000004896 & $2,1 E+04$ & 0,010 \\
\hline $2,858 E-01$ & $2,0 E+06$ & 0,0000004897 & $2,1 E+04$ & 0,010 \\
\hline $2,959 E-01$ & $2,0 E+06$ & 0,0000004897 & $4,1 E+04$ & 0,020 \\
\hline $3,161 E-01$ & $2,0 E+06$ & 0,0000004897 & $5,0 E+05$ & 0,243 \\
\hline
\end{tabular}

and the reliability index could be expressed as [26]:

$$
\beta=\frac{m_{G}}{s_{G}}=\frac{m_{R}-m_{E}}{\sqrt{s_{R}^{2}+s_{E}^{2}}} .
$$

The aforementioned procedure could be specified to the bridge case study, where the calculated probability of fatigue fracture to obtain the probability of failure could be estimated as:

$$
P_{f}=P_{\text {fat }}\left(1-P_{\text {det }}\right),
$$

where $P_{f}$ is failure probability; $P_{\text {fat }}$ is probability of fatigue fracture; $P_{\text {det }}$ is probability of crack detection that is considered zero $\left(P_{\mathrm{det}}=0\right)$ since structural health monitoring 


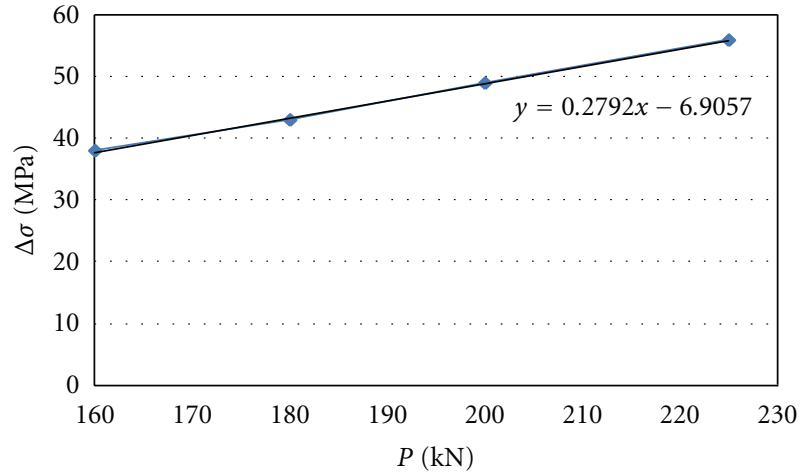

FIgure 6: Load-stress relation for detail 1.

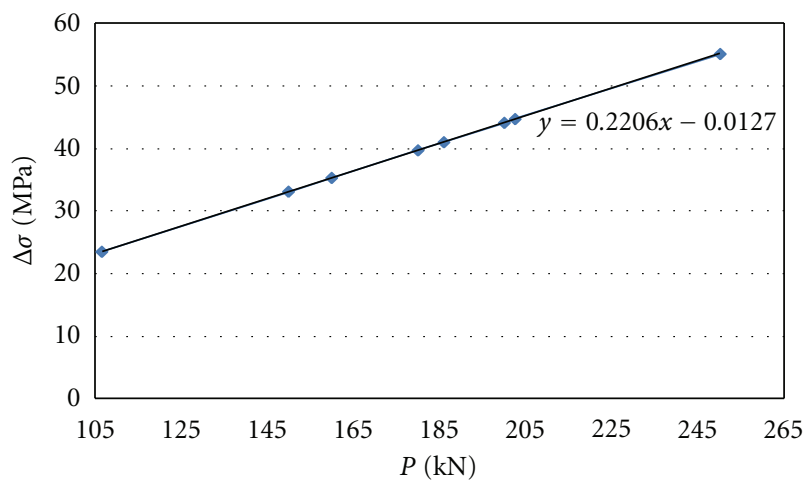

FIGURE 7: Load-stress relation for detail 2.

system has been used on the bridge $[27,28]$. The probability of failure can also be expressed with the reliability index according to the normal standard distribution. Finally the reliability of a structural element is compared to the target value:

$$
\beta_{\text {fail }} \geq \beta_{\text {target }},
$$

where $\beta_{\text {fail }}$ is reliability index with respect to failure; $\beta_{\text {target }}$ is target reliability index. This model implies the use of the fatigue action effect (the required nominal fatigue strength) as "required operational load factor $\alpha_{\text {req }}$ " which is obtained by dividing the required nominal fatigue strength by the action effect of the fatigue load:

$$
\alpha_{\text {req }}=\frac{\Delta \sigma_{C, \text { req }}}{\Delta \sigma\left(\Phi Q_{\mathrm{fat}}\right)},
$$

where $\Delta \sigma_{C, \text { req }}$ is the required nominal fatigue strength; $\alpha_{\text {req }}$ is the required operational load factor; $\Delta \sigma\left(\Phi Q_{\text {fat }}\right)$-stress range due to the load model adopted at worst position $\left(Q_{\mathrm{fat}}\right)$, considering the dynamic amplification $(\Phi$, e.g., maximizing the fatigue stress amplitude). For a simplified probabilistic approach, a relation between mean value of required operational load factor $m\left(\log \alpha_{\text {req }}\right)$ and number of future train passages $N_{\text {fut }}$ has been introduced [28]. The mean of the required operational load factor $m\left(\log \alpha_{\text {req }}\right)$ is then read for fatigue category chosen (expressed as $N_{D}$, number of load cycles corresponding to the constant-amplitude fatigue limit) starting from a number of future trains $N_{\text {fut }}$ (as from 2005); this relation could be used for any influence lengths [28], commissioning time, and freight traffic fraction. According to the same model, a value of 0.04 may be taken as standard deviation of the required operational load factors, resulting from the assumed fuzziness of the traffic model [28]. Adopting the following notation and assumption:

$$
\beta\left(N_{\text {fut }}\right)=\frac{m_{R}-m_{E}\left(N_{\text {fut }}\right)}{\sqrt{s_{R}^{2}+s_{E}^{2}}},
$$

where $s_{E}$ is the standard deviation of the required fatigue strength; $\beta_{\left(N_{\text {fut }}\right)}$ is the reliability index; $m_{r}=\log \Delta \sigma_{c}+2 s_{r}$ is the mean of the fatigue strength $(\log \Delta \sigma$ relating to $2 \times$ $10^{6}$ cycles $) ; m_{E}\left(N_{\text {fut }}\right)=m\left(\log \alpha_{\text {req }}\right)+\log \Delta \sigma\left(\Phi \cdot Q_{\text {fat }}\right)$ is the mean of the required fatigue strength as a function of the number of future trains $N_{\text {fut }} ; s_{R}=s \log (N) / m$ is the standard deviation of the fatigue strength where $m$ is the slope of the $S$ - $N$ curve, and $s(\log N)$ is the standard deviation of test results; $s_{E}$ is the standard deviation of the fatigue strength. It should be observed that the variability in $S-N$ curve is only on life and not on stress range and that the variability of stress for a given life is not statistically related to variability of life for a given stress. Specific values of $\beta$ are recommended for a determinate remaining service life, according to ISO/CD 13822 [29]: for the assessment of existing structures and the fatigue limit state, reference indexes should be $\beta_{\max }=3.1$ for not visible detail and $\beta_{\min }=2.3$ for visible detail. The reliability model herein presented has been related to the aforementioned traffic spectra and loadings.

2.3. Damage Accumulation. Due to the inherent disadvantage of the $S-N$ curve approach, which cannot incorporate information on crack size, an alternative approach based on LEFM concepts $[30,31]$ is considered in this study. The LEFM approach is based on crack propagation theory [3235]. The Paris law [36], the most common LEFM-based crack growth model, is used since it retains the simplicity of the fatigue evaluation process. This can be described as:

$$
\frac{d a}{d N}=C \cdot \Delta K^{m},
$$

where $a$ is the crack size, $N$ is the number of stress cycles, $C$ and $m$ are material constants and $\Delta K$ is the stress intensity range. According to LEFM theory [31], $\Delta K$ can be estimated as:

$$
\Delta K=Y(a) \cdot \Delta \sigma \sqrt{\pi \cdot a},
$$

where $\Delta \sigma$ is the tensile stress range, $Y(a)$ is the geometry function to take into account stress concentrations [37], such as, the stress concentration coefficient and the dimensions of the specimen under consideration. It is not completely clear how the stress cycles below a constant amplitude fatigue limit affect the fatigue life [38]. Stress cycles due to live loads could be lower than the fatigue limit [39] and in these particular cases, according to Miner's rule [40] and to damage verifications based on Eurocodes (e.g., [41]), 
TABLE 5: Model adopted for the cycle counting (e.g., UIC A03 train, from 1900-1908).

\begin{tabular}{lccccccccc}
\hline Period & Train & Train/day & Tractor (L) carriage (Ci) & kN/axle & $n^{\circ}$ axles & $n^{\circ}$ carriage & Axles/day & $\Sigma F[\mathrm{kN}]$ & $n^{\circ}$ Axles/year \\
\hline & & 17,2 & $\mathrm{~L}$ & 140,00 & 3 & 1 & 51,5 & 420 & $1,9 E+04$ \\
& & 17,2 & $\mathrm{~L}$ & 120,00 & 2 & 1 & 34,3 & 240 & $1,3 E+04$ \\
\multirow{3}{*}{$1900-1908$} & \multirow{2}{*}{$\mathrm{A} 03$} & 17,2 & $\mathrm{~L}$ & 100,00 & 1 & 1 & 17,2 & 100 & $6,3 E+03$ \\
& & 17,2 & $\mathrm{C} 1$ & 50,00 & 3 & 6 & 308,9 & 900 & $1,1 E+05$ \\
\hline & & & & & Tot. & 411,8 & 1660 & $1,5 E+05$ \\
\hline
\end{tabular}

TABLE 6: Model adopted for the damage calculation (e.g., UIC A03 train, from 1900-1908).

\begin{tabular}{lccccccccccc}
\hline$\Delta \sigma$ & $\Phi$ & $\phi^{*} \Delta \sigma$ & $m$ & $\Delta \sigma_{\text {th }}$ & $\Delta \sigma_{c, \text { req }}$ & $D=\Sigma d_{i}$ & $N_{c}$ & $d_{i}$ & $R_{i}$ & $d_{i} \times R_{i}$ \\
\hline 62,0 & 1,245 & 77,19 & 3 & 73,70 & 100 & $0,00 E+00$ & $2,0 E+06$ & $3,62 E-08$ & $1,7 E+05$ & 0,006 \\
60,0 & 1,245 & 74,70 & 3 & 73,70 & 100 & $6,12 E-03$ & $2,0 E+06$ & $1,38 E-08$ & $1,1 E+05$ & 0,002 \\
22,0 & 1,245 & 27,45 & 3 & 73,55 & 100 & $7,67 E-03$ & $2,0 E+06$ & $0,00 E+00$ & $5,6 E+04$ & 0,000 \\
11,0 & 1,245 & 13,72 & 3 & 73,51 & 100 & $7,67 E-03$ & $2,0 E+06$ & $0,00 E+00$ & $1,0 E+06$ & 0,000 \\
\hline
\end{tabular}

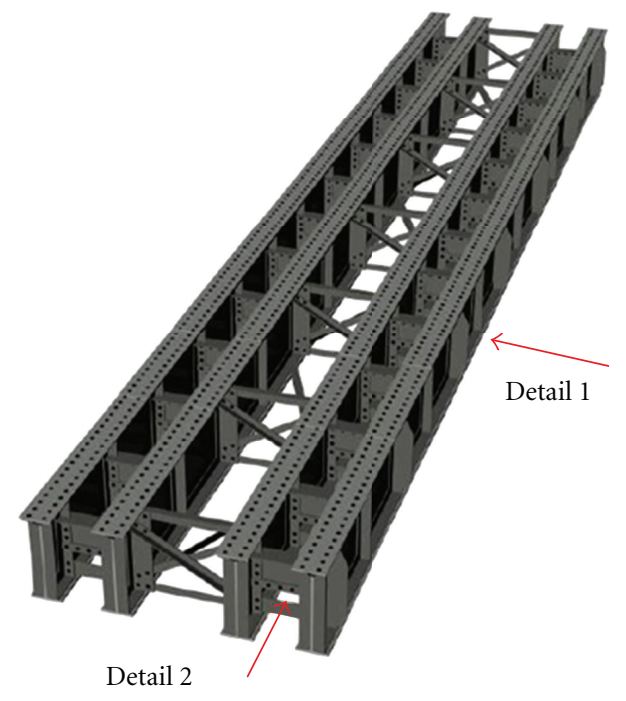

FIGURE 8: Details considered: midspan inferior flange (1) and short shear diaphragm (2).

they should not produce any damage. The damage model developed in this paper considers the damage due to stress cycles below the cut-off limit which causes a damage in term of crack propagation according to LEFM principles [42]. The adopted damage model implies that stress ranges are damage effective only if $\Delta \sigma_{\text {th }}$ is exceeded, where $\Delta \sigma_{\text {th }}$ is the damage limit and $\Delta \sigma_{D}$ is the fatigue limit for constant amplitude stress ranges at the number of cycles $N=5 * 10^{6}$, defined by [30] and taking $a_{0}$ as the initial crack size, the $\Delta \sigma_{\text {th }}$ could be expressed as:

$$
\Delta \sigma_{\mathrm{th}}=\Delta \sigma_{D} \frac{Y\left(a_{0}\right) \cdot \sqrt{\pi \cdot a_{0}}}{Y(a) \cdot \sqrt{\pi \cdot a}} .
$$

That could be written as

$$
\Delta \sigma_{\mathrm{th}}=\Delta \sigma_{D} f(D)
$$

being

$$
f(D)=\frac{Y\left(a_{0}\right) \cdot \sqrt{\pi \cdot a_{0}}}{Y(a) \cdot \sqrt{\pi \cdot a}} .
$$

Combining (15) and (16), with $Y=$ constant,

$$
\frac{d a}{d N}=C \cdot Y^{m} \cdot \Delta \sigma^{m} \cdot(\pi \cdot a)^{m / 2},
$$

and taking

$$
\begin{gathered}
B=C \cdot Y^{m} \cdot \Delta \sigma^{m} \cdot \pi^{m / 2}, \\
\frac{d a}{d N}=B \cdot a^{m / 2} .
\end{gathered}
$$

Equation (22) can be written as

$$
\int_{a 0}^{a i} a^{m / 2} d a=\int_{0}^{N i} B d N
$$

in which $a_{i}$ is the depth of the crack at a number of cycles equal to $N_{i}$. According to Kunz [30] the initial size of the crack $a_{0}=0.1 \mathrm{~mm}$. According to Bremen [43], (15) could be also written as:

$$
\frac{d a}{d N}=C \cdot\left(\Delta K^{m}-\Delta K_{\mathrm{th}}^{m}\right) .
$$

And according to (16),

$$
\Delta K_{\mathrm{th}}=Y(a) \cdot \Delta \sigma_{\mathrm{th}} \sqrt{\pi \cdot a} .
$$

It follows that

$$
\begin{aligned}
\frac{d a}{d N}= & C \cdot Y(a)^{m} \cdot(\pi \cdot a)^{m / 2} \\
& \cdot\left(\Delta \sigma^{m}-\Delta \sigma_{\mathrm{th}}^{m}\right) \\
\int_{a 0}^{\mathrm{acrit}} Y(a)^{-m} \cdot a^{-m / 2} d a & =\int_{0}^{N} C \cdot \pi^{m / 2} \cdot\left(\Delta \sigma^{m}-\Delta \sigma_{\mathrm{th}}^{m}\right) d N \\
& =C \cdot \pi^{m / 2} \cdot\left(\Delta \sigma^{m}-\Delta \sigma_{\mathrm{th}}^{m}\right) \cdot N .
\end{aligned}
$$



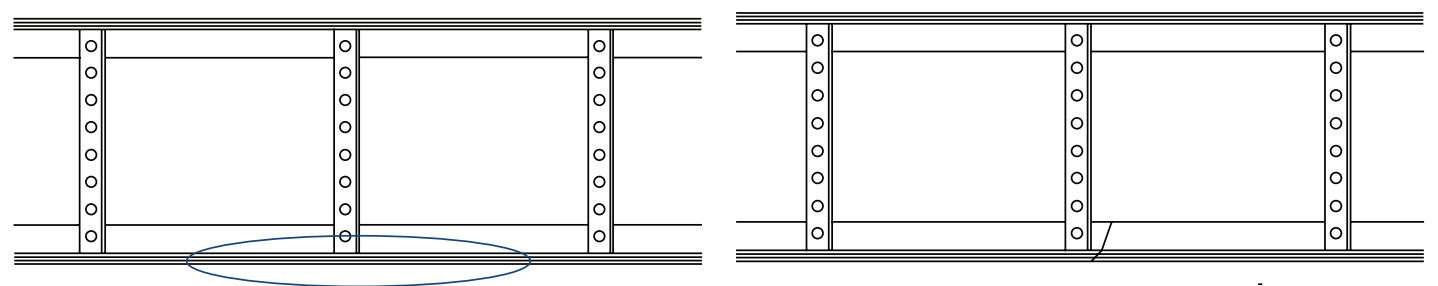

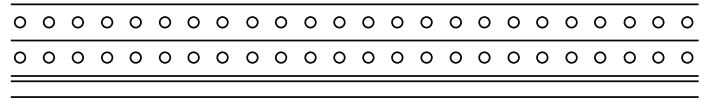

(a)

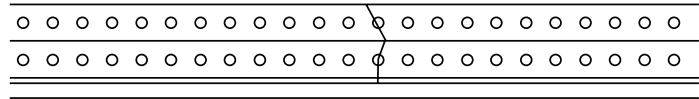

(b)

Figure 9: Midspan bottom flange (a) and typical failure (b).

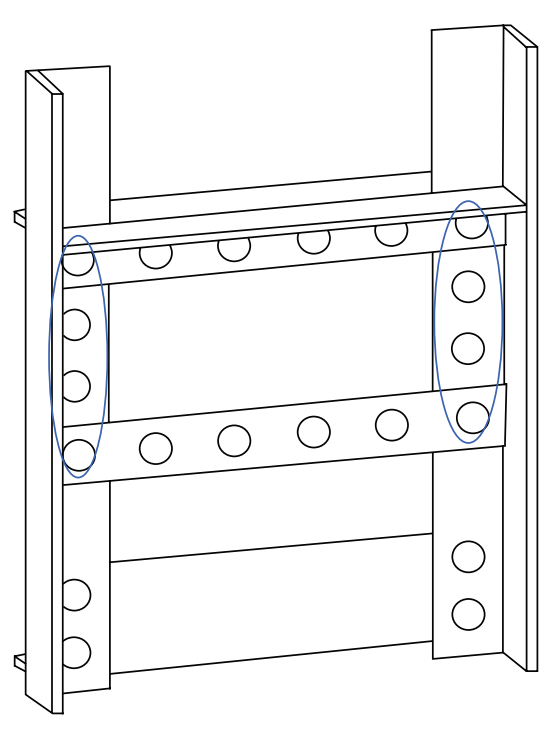

(a)

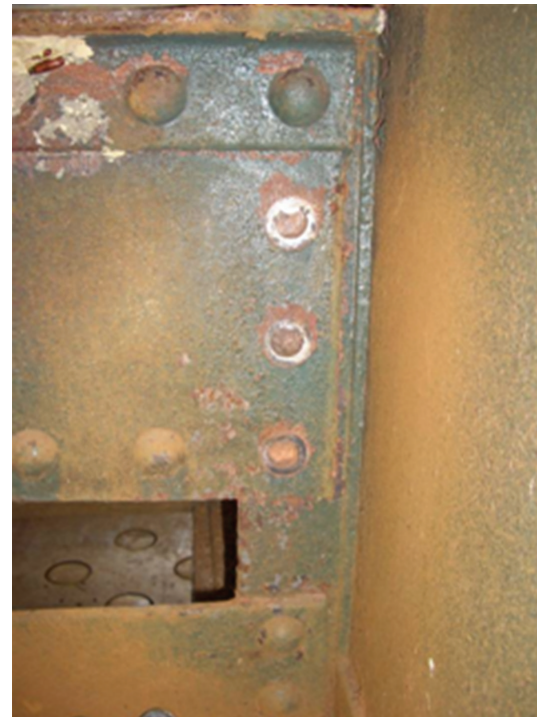

(b)

FIGURE 10: Riveted connection of the short-shear diaphragm (a) and typical failure (b).

And being constant

$$
\frac{\int_{a 0}^{\text {acrit }} Y(a)^{-m} \cdot a^{-m / 2} d a}{C \cdot \pi^{m / 2}} .
$$

It follows that

$$
\begin{gathered}
\left(\Delta \sigma^{m}-\Delta \sigma_{\mathrm{th}}^{m}\right) \cdot N=\text { constant } \\
\left(\Delta \sigma_{i}^{m}-\Delta \sigma_{\mathrm{th}}^{m}\right) \cdot N_{i}=\left(\Delta \sigma_{k}^{m}-\Delta \sigma_{\mathrm{th}}^{m}\right) \cdot N_{k} \\
d_{i}=\frac{1}{N i} .
\end{gathered}
$$

The single damage increases, taking $\Delta \sigma_{\text {th }}$ as the cut-off limit and $\Delta \sigma_{k}$ as the category detail at the number of cycles $N=$ $2 * 10^{6}$, according to Kunz [30] is represented by:

$$
d_{i}=\frac{\Delta \sigma_{i}^{m}-\Delta \sigma_{\mathrm{th}}^{m}}{\Delta \sigma_{k}^{m}-\Delta \sigma_{\mathrm{th}}^{m}} \cdot \frac{1}{N_{k}},
$$

where $\Delta \sigma_{i}=$ applied stress range, $m=S$ - $N$ curve slope, $D=$ total damage.

Failure will occur when the accumulated damage $D=$ $\Sigma d_{i}=1$, according to Miner [40]. In the case study analyzed, the bridge has been built in 1918 and dismantled in 2005 . Table 4 shows that damage accumulation starts with A05 UIC train (1909-1923), and all the following trains contribute to the damage as reported. For every train type contributing to damage, the number of cycles of the detail category $\left(N_{c}\right)$, the damage increasing $\left(d_{i}\right)$, the axles number passed at the end of the period $\left(R_{i}\right)$ are reported. Category $C=112$ for bending detail and $C=100$ for shear detail has been assumed, as suggested by EN 1993-1-9 [41]: the category detail reference has been made according to Eurocode indications. Load models are described by concentrated characteristic axle load that implies cycle fluctuation in the structural components: stress variations $(\Delta \sigma, \Delta \tau)$ have been counted as per ASTM [44]. Basing on real scale structural tests 
TABLe 7: Reliability analysis 2005-future, detail1, load model A.

\begin{tabular}{lccccc}
\hline Year & $N_{\text {fut }}$ & $\beta_{\max }$ & $\beta_{\min }$ & $\beta\left(N_{\text {fut }}\right)$ & Status \\
\hline 2005 & $2,09 E+05$ & 3,1 & 2,3 & 2,71 & In service \\
2010 & $5,36 E+05$ & 3,1 & 2,3 & 2,65 & In service \\
2015 & $8,76 E+05$ & 3,1 & 2,3 & 2,59 & In service \\
2020 & $1,23 E+06$ & 3,1 & 2,3 & 2,54 & In service \\
2025 & $1,59 E+06$ & 3,1 & 2,3 & 2,48 & In service \\
2030 & $1,96 E+06$ & 3,1 & 2,3 & 2,42 & In service \\
2035 & $2,35 E+06$ & 3,1 & 2,3 & 2,37 & In service \\
2040 & $2,74 E+06$ & 3,1 & 2,3 & 2,32 & In service \\
2045 & $3,14 E+06$ & 3,1 & 2,3 & 2,26 & Out of service in 2043 \\
\hline
\end{tabular}

TABLE 8: Reliability analysis 2005-future, detail1, load model B.

\begin{tabular}{lccccc}
\hline Year & $N_{\text {fut }}$ & $\beta_{\max }$ & $\beta_{\min }$ & $\beta\left(N_{\text {fut }}\right)$ & Status \\
\hline 2005 & $2,09 E+05$ & 3,1 & 2,3 & 2,57 & In service \\
2010 & $5,36 E+05$ & 3,1 & 2,3 & 2,48 & In service \\
2015 & $8,76 E+05$ & 3,1 & 2,3 & 2,41 & In service \\
2020 & $1,23 E+06$ & 3,1 & 2,3 & 2,36 & In service \\
2025 & $1,59 E+06$ & 3,1 & 2,3 & 2,34 & In service \\
2030 & $1,96 E+06$ & 3,1 & 2,3 & 2,34 & In service \\
2035 & $2,35 E+06$ & 3,1 & 2,3 & 2,34 & In service \\
2040 & $2,74 E+06$ & 3,1 & 2,3 & 2,34 & In service \\
2045 & $3,14 E+06$ & 3,1 & 2,3 & 2,32 & In service \\
2050 & $3,55 E+06$ & 3,1 & 2,3 & 2,29 & Out of service in 2049 \\
\hline
\end{tabular}

TABLE 9: Reliability analysis 2005-future, detail 2, load model A.

\begin{tabular}{cccccc}
\hline Year & $N_{\text {fut }}$ & $\beta_{\max }$ & $\beta_{\min }$ & $\beta\left(N_{\text {fut }}\right)$ & Status \\
\hline 2005 & $2,09 E+05$ & 3,1 & 2,3 & 2,80 & In service \\
2010 & $5,36 E+05$ & 3,1 & 2,3 & 2,63 & In service \\
2015 & $8,76 E+05$ & 3,1 & 2,3 & 2,46 & In service \\
2020 & $1,23 E+06$ & 3,1 & 2,3 & 2,31 & In service \\
2025 & $1,59 E+06$ & 3,1 & 2,3 & 2,17 & Out of service in 2021 \\
\hline
\end{tabular}

TABle 10: Reliability analysis 2005-future, detail 2, load model B.

\begin{tabular}{lccccc}
\hline Year & $N_{\text {fut }}$ & $\beta_{\max }$ & $\beta_{\min }$ & $\beta\left(N_{\text {fut }}\right)$ & Status \\
\hline 2005 & $2,09 E+05$ & 3,1 & 2,3 & 2,65 & In service \\
2010 & $5,36 E+05$ & 3,1 & 2,3 & 2,52 & In service \\
2015 & $8,76 E+05$ & 3,1 & 2,3 & 2,43 & In service \\
2020 & $1,23 E+06$ & 3,1 & 2,3 & 2,36 & In service \\
2025 & $1,59 E+06$ & 3,1 & 2,3 & 2,32 & In service \\
2030 & $1,96 E+06$ & 3,1 & 2,3 & 2,28 & Out of service in 2027 \\
\hline
\end{tabular}

[45] a linear correlation between axle load $(P)$ and stress variations, without dynamic amplification factor, has been reported in Figures 6 and 7. Moreover, Table 5 reports the cycle counting model adopted, while in Table 6 a damage calculation example making reference to a single train, UIC A03 from 1900-1908 is reported.

2.4. Calculation of Reliability Index. The reliability analysis of detail 1 and 2 (Figures 8, 9, and 10) has been performed assuming the methodology described above and by adopting the aforementioned load models, applied to the hot-spot details: the midspan bottom flange and the riveted connection of the short shear diaphragm transverse connecting the principle beams. Table 7 reports the analysis from 2005future for detail 1 and load method A, while Table 8 for load method B. Table 9 reports the analysis from 2005-future for detail 2 and load method A, Table 10 for load method B: as could be observed, these tables illustrate the increasing 


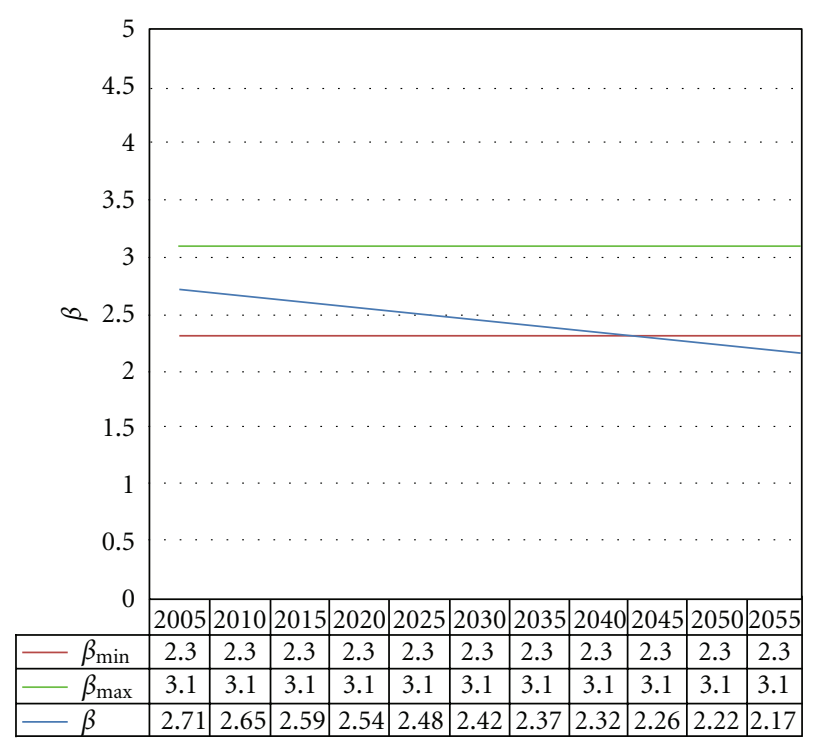

Figure 11: Reliability trend, detail 1, load model A.

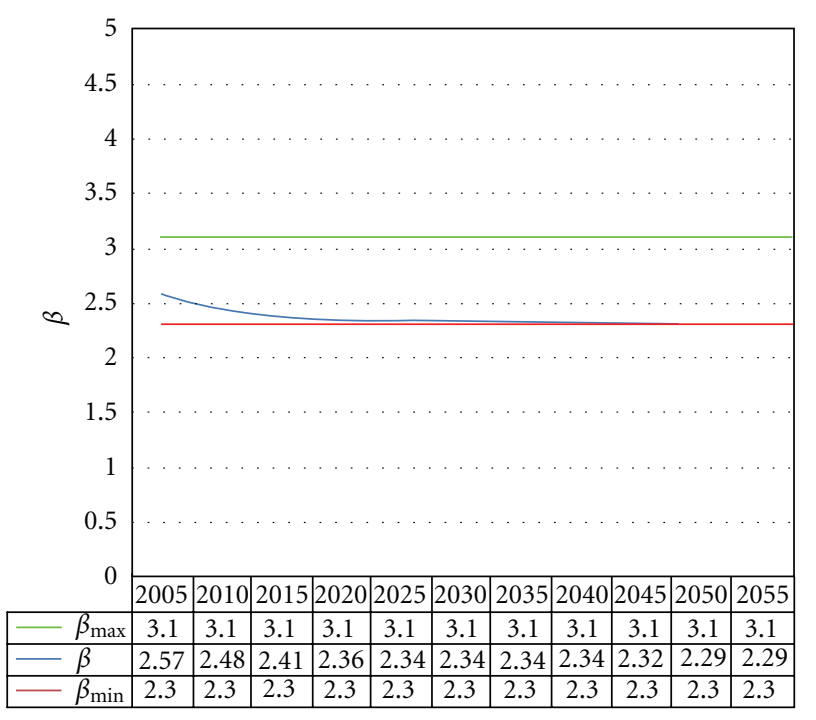

FIGURE 12: Reliability trend, detail 1, load model B.

number of future trains $\left(N_{\text {fut }}\right)$, the value of $\beta_{\max }$ and $\beta_{\min }$, the decreasing value of $\beta\left(N_{\text {fut }}\right)$, and the bridge status according to this analysis; moreover, the precise value of the out of service year is reported at the end of the bridge damage lifecycle. According to these values, the reliability index trends are plotted (Figures 11, 12, 13, and 14). Moreover, the hypothesis to repair the detail 2 has been analyzed: the precise time interval has been identified in the average value $\beta=2,70=$ $\left(\beta_{\max }-\beta_{\min }\right) / 2$ (Figure 15). Results have highlighted that the detail 1 , assuming the load model $\mathrm{A}$, will reach the out of service in 2043, while the same detail loaded with the model B terminates in 2049; the detail 2, the hot spot of this structure, based on the load model A will be the out of service in 2021, while the same detail loaded with the model B goes out of service in 2027: by repairing the more damaged detail

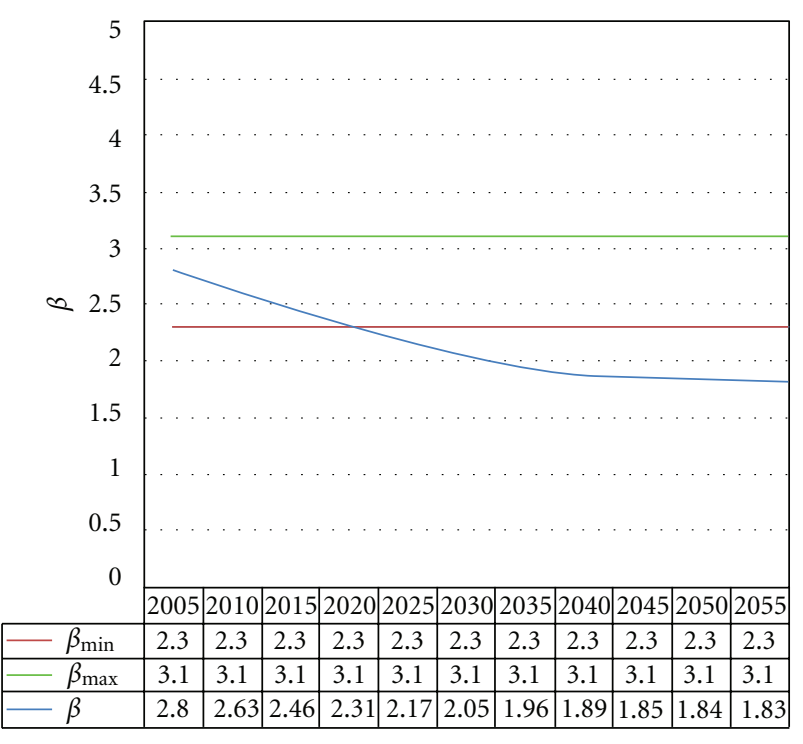

FIGURE 13: Reliability trend, detail 2, load model A.

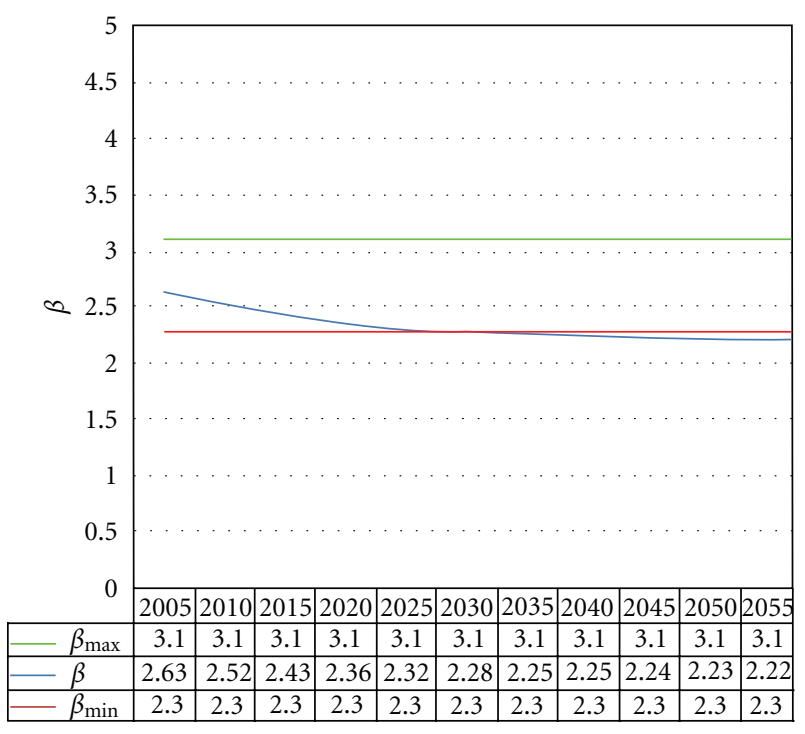

FIgURE 14: Reliability trend, detail 2, load model B.

2 , it is possible to increase the service life of the bridge of about 12 years.

\section{Conclusions}

This work deals with the estimation of the fatigue damage in existing railway metal bridges and the remaining fatigue life according to a detailed loading history analysis. The method is then applied to a real case study. In terms of loadings, a detailed loading history analysis has been performed by adopting two different load methods, A and B: the historical loadings have been assumed according to UIC 779-1 [21]; from 1991 to 2000, the traffic spectrum has been based on the Instruction 44/F [25]; from 2001 up to now, loads refer to LM71 load model (method A) or to Instruction $44 / \mathrm{F}$ 


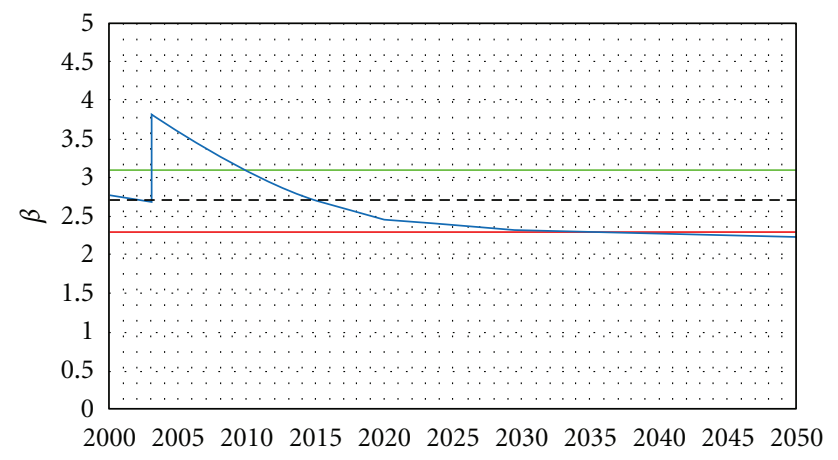

FIGURE 15: Reliability trend, detail 2, load model B, repair hypothesis.

(method B). It was confirmed that the critical fatigue detail of the bridge is located in the riveted connection of the short-shear diaphragm connecting principle beams as shown in previous mentioned studies. Moreover, different results according to different load methods related to the future traffic (i.e., load A and load B) should influence the expected fatigue life; in particular, a more realistic fatigue load model (load A) could lead to an extension of the fatigue life of the investigated bridge; on the contrary, an assessment based on conservative and approximate code load model could lead to a shorter lifetime prediction. The method described in this work enables a better understanding of the damage level in steel bridges, and could help to maintain in service existing bridges, adopting detailed loading history analysis. As a matter of fact, managing authorities should be aware of the possibility to correctly estimate residual life of existing infrastructure, for example, by implementing maintenance program based on advanced analytical assessment.

\section{Acknowledgment}

The authors wish to thank Mr. M. Gueli for contributing to some numerical analyses developed during the thesis. The research conclusions are only the views of the authors.

\section{References}

[1] C. Pellegrino, A. Pipinato, and C. Modena, "A simplified management procedure for bridge network maintenance," Structure and Infrastructure Engineering, vol. 7, no. 5, pp. 341351, 2011.

[2] A. Pipinato, C. Pellegrino, and C. Modena, "Fatigue assessment of highway steel bridges in presence of seismic loading," Engineering Structures, vol. 33, no. 1, pp. 202-209, 2010.

[3] A. Pipinato, C. Pellegrino, O. S. Bursi, and C. Modena, "Highcycle fatigue behavior of riveted connections for railway metal bridges," Journal of Constructional Steel Research, vol. 65, no. 12, pp. 2167-2175, 2009.

[4] A. Pipinato, M. Molinari, C. Pellegrino, O. Bursi, and C. Modena, "Fatigue tests on riveted steel elements taken from a railway bridge," Structure and Infrastructure Engineering, vol. 7, no. 12, pp. 907-920, 2009.

[5] A. Pipinato and C. Modena, "Structural analysis and fatigue reliability assessment of the paderno bridge," Practice
Periodical on Structural Design and Construction, vol. 15, no. 2, pp. 109-124, 2010.

[6] A. Pipinato, C. Pellegrino, and C. Modena, "Assessment procedure and rehabilitation criteria for the riveted railway Adige bridge," Structure and Infrastructure Engineering, vol. 8, no. 8, pp. 747-764, 2010.

[7] A. Pipinato, "Step level procedure for remaining fatigue life evaluation of one railway bridge," Baltic Journal of Road and Bridge Engineering, vol. 5, no. 1, pp. 28-37, 2010.

[8] E. Bruhwiler, I. F. C. Smith, and M. A. Hirt, "Fatigue and fracture of riveted bridge members," Journal of Structural Engineering, vol. 116, no. 1, pp. 198-214, 1990.

[9] G. L. Kulak, "Discussion of fatigue strength of riveted bridge members, by J.W. Fisher, B.T. Yen, D. Wang," Journal of Structural Engineering, vol. 116, no. 11, pp. 2968-2981, 1990.

[10] B. Akesson and B. Edlund, "Remaining fatigue life of riveted railway bridges," Stahlbau, vol. 65, no. 11, pp. 429-436, 1996.

[11] J. D. Di Battista, D. E. J. Adamson, and G. L. Kulak, "Fatigue strength of riveted connections," Journal of Structural Engineering, vol. 124, no. 7, pp. 792-797, 1998.

[12] O. S. Bursi, F. Ferrario, and V. Fontanari, "Non-linear analysis of the low-cycle fracture behaviour of isolated Tee stub connections," Computers and Structures, vol. 80, no. 27-30, pp. 2333-2360, 2002.

[13] E. B. Matar and R. Greiner, "Fatigue test for a riveted steel railway bridge in Salzburg," Structural Engineering International, vol. 16, no. 3, pp. 252-260, 2006.

[14] M. I. Boulent, T. D. Righiniotis, and M. K. Chryssanthopoulos, "Probabilistic fatigue evaluation of riveted railway bridges," Journal of Bridge Engineering, vol. 13, no. 3, pp. 237-244, 2008.

[15] P. Albrecht and A. Lenwari, "Design of prestressing tendons for strengthening steel truss bridges," Journal of Bridge Engineering, vol. 13, no. 5, pp. 449-454, 2008.

[16] B. Kühn, M. Lukič, A. Nussbaumer et al., "Assessment of existing steel structures, Recommendations for estimation of the remaining fatigue life," Joint Research Centre-European Convention for Constructional Steelwork Report, 2008.

[17] P. Albrecht and A. Lenwari, "Variable-amplitude fatigue strength of structural steel bridge details: review and simplified model," Journal of Bridge Engineering, vol. 14, no. 4, pp. 226237, 2009.

[18] E. Brühwiler, M. A. Hirt, and V. Fontanari, "Umgang mit genieteten Bahnbrücken von hohem kulturellem Wert," Stahlbau, vol. 79, no. 3, pp. 209-219, 2010.

[19] American Society of Civil Engineers (ASCE), "Committee on fatigue and fracture reliability of the committee on structural safety and reliability of the structural division. Fatigue reliability 1-4," Journal of Structural Division, vol. 108, pp. 83-88, 1982.

[20] W. G. Byers, M. J. Marley, J. Mohammadi, R. J. Nielsen, and S. Sarkani, "Fatigue reliability reassessment applications: stateof-the-art paper," Journal of Structural Engineering, vol. 123, no. 3, pp. 277-285, 1997.

[21] UIC, Leaflets 779-1 R: Recommendations for the Evaluation of the Load Carrying Capacity of Existing Steel Bridges, International Union of Railways, Utrecht, The Netherlands, 1988.

[22] EN 1991-2, Eurocode 1: Action on Structures-Part 2-Load on Bridges, Comité Européen de Normalisation (CEN), Brussels, Belgium, 2005.

[23] CER, International railway traffic CER, Community of european railway and infrastructure companies, 2009.

[24] A. Keller, E. Brühwiler, and M. A. Hirt, "Assessment of a 135 year old riveted railway bridge," in Extending the Lifespan 
of Structures, vol. 73/2, pp. 1029-1034, IABSE Symposium Report, San Francisco, Calif, USA, 1995.

[25] Instruction 44/F, Verifica a Fatica dei Ponti Ferroviari, Technical Code of Italian Railway Authority, Milan, Italy, 1992.

[26] C. A. Cornell, "Bounds on the reliability of structural systems," Journal of Structural Division, vol. 93, pp. 171-200, 1967.

[27] A. Coppe, R. T. Haftka, N. H. Kim, and C. Bes, "A statistical model for estimating probability of crack detection," in Proceedings of the International Conference on Prognostics and Health Management (PHM '08), pp. 1-5, October 2008.

[28] Sustainable Bridges, Guideline for Load and Resistance Assessment of Existing European Railway Bridges-Advices on the use of advanced methods. European research project under the EU 6th framework programme, http://www.sustainablebridges .net/, 2006.

[29] ISO 13822, Basis for Design of Structures-Assessment of Existing Structures, ISO-International Organization for Standardization, Geneva, Switzerland, 2010.

[30] P. Kunz, Probabilistisches verfahren zur beurteilung der ermuedungssicherheit bestehender bruecken aus stahlPh.D. thesis Number 1023, Swiss Federal Institute of Technology, Lausanne, Switzerland, 1992.

[31] M. S. Cheung and W. C. Li, "Probabilistic fatigue and fracture analyses of steel bridges," Structural Safety, vol. 25, no. 3, pp. 245-262, 2003.

[32] D. O. Harris, "Probabilistic fracture mechanics," in Probabilistic Structural Mechanics Handbook, C. Sundararajan, Ed., pp. 106-145, Chapman \& Hall, New York, NY, USA, 1995.

[33] K. Ortiz and A. S. Kiremidjian, "Stochastic modeling of fatigue crack growth," Engineering Fracture Mechanics, vol. 29, no. 3, pp. 317-334, 1988.

[34] G. F. Oswald and G. I. Schuëller, "Reliability of deteriorating structures," Engineering Fracture Mechanics, vol. 20, no. 3, pp. 479-488, 1984.

[35] J. L. Bogdanoff and F. Kozin, Probabilistic Models of Cumulative Damage, Wiley, New York, NY, USA, 1985.

[36] P. Paris and F. Erdogan, "A critical analysis of crack propagation laws," Journal of Basic Engineering, vol. 85, no. 4, pp. 528534, 1963.

[37] Y. Murakami, Stress Intensity Factors Handbook, Pergamon Press, Oxford, UK, 1987.

[38] K. Yamada, C. Qiuliang, and O. Naoki, "Fatigue crackgrowth measurements under spectrum loading," Engineering Fracture Mechanics, vol. 66, no. 5, pp. 483-497, 2000.

[39] S. K. Raju, F. Moses, and C. G. Schilling, "Reliability calibration of fatigue evaluation and design procedures," Journal of Structural Engineering, vol. 116, no. 5, pp. 1356-1369, 1990.

[40] M. A. Miner, "Cumulative damage in fatigue," Journal of Applied Mechanics, vol. 12, no. 3, pp. A159-A164, 1945.

[41] EN 1993-1-9, Eurocode 3: Design of Steel Structures-Part 1-9: Fatigue, Comité Européen de Normalisation (CEN), Brussels, Belgium, 2005.

[42] A. Keller, E. Bruhwiler, and M. A. Hirt, Assessment of a 135 Year Old Riveted Railway Bridge, IABSE Colloquium, Copenhagen, Denmark, 1993.

[43] U. Bremen, Amelioration du comportement a la fatigue d'assemblages soudes: etudes de modelisation de l'effet de contraintes residuelles, Graduation thesis, École Polytechnique Fédérale de Lausanne, Vaud, Switzerland, 1989.

[44] American Society for Testing and Materials (ASTM), ASTM E1049-85: Standard Practices for Cycle Counting in Fatigue Analysis, American Society for Testing and Materials, New York, NY, USA, 2005.
[45] A. Pipinato, High-cycle fatigue behaviour of historical metal riveted railway bridges, Ph.D. thesis, University of Padova, Padova, Italy, 2008. 

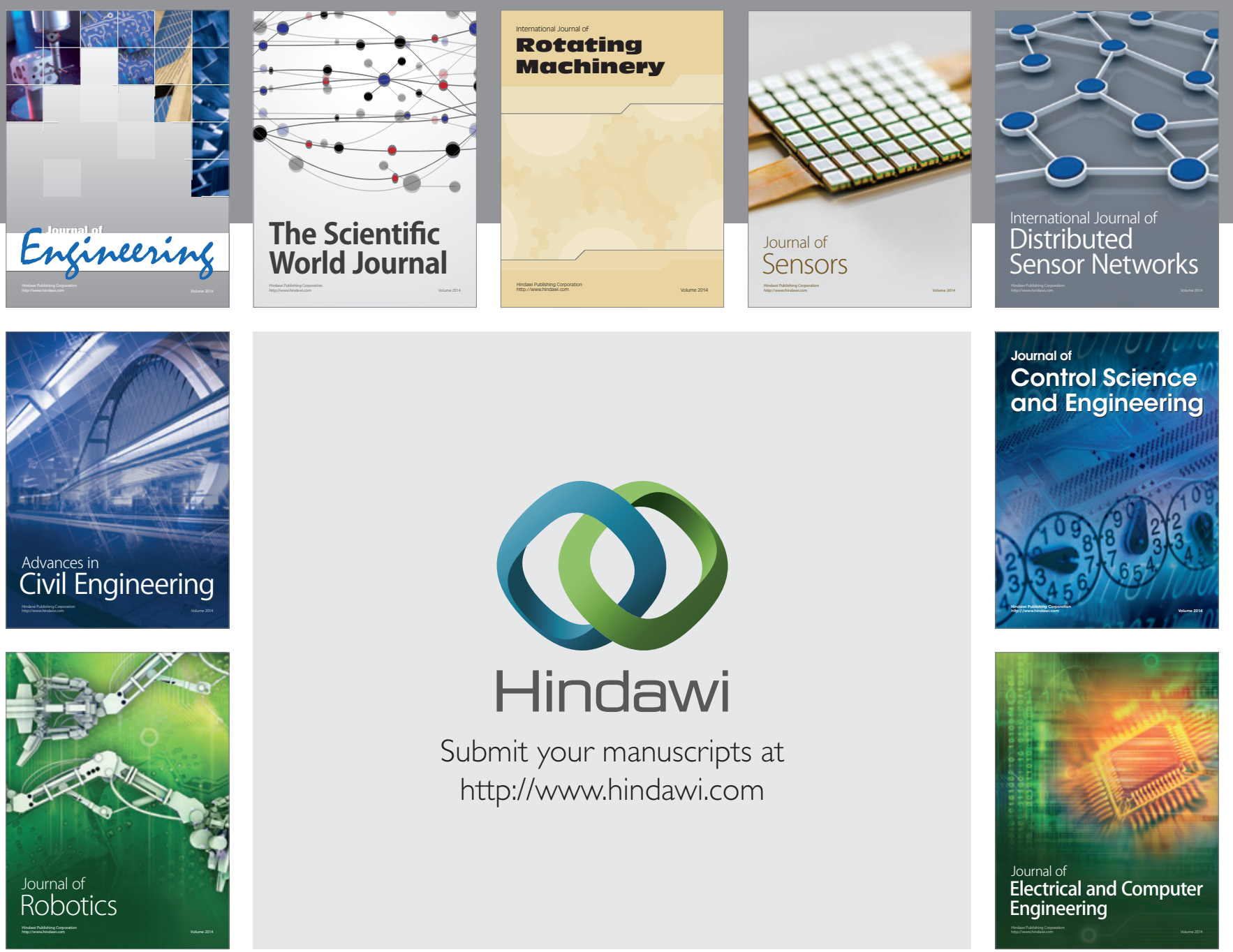

Submit your manuscripts at

http://www.hindawi.com
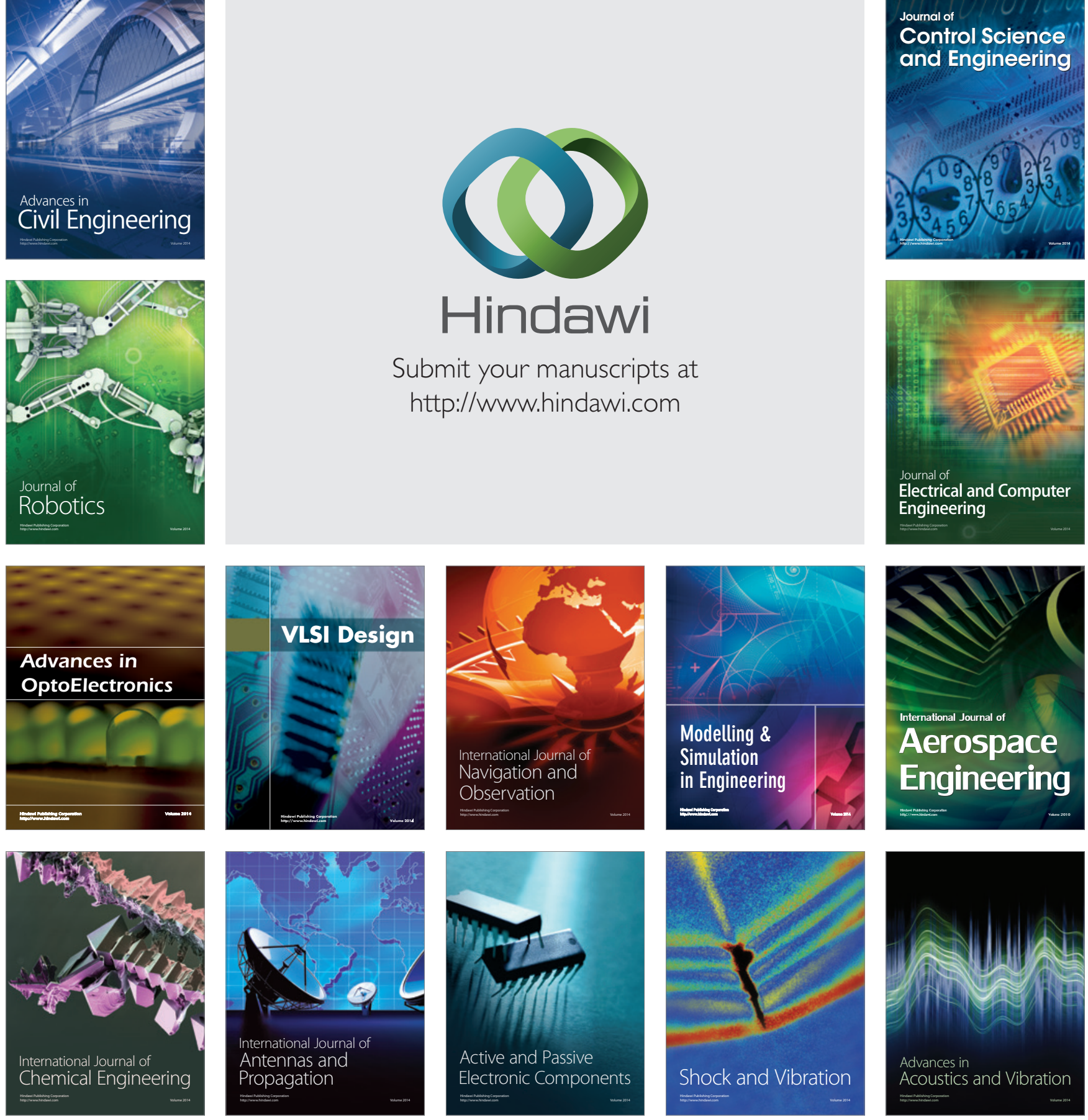